\title{
Manajemen Panen Kelapa Sawit (Elaeis gueneensis Jacq.) di Seruyan Estate, Kebun Minamas, Kalimantan Tengah
}

\author{
Harvest Management of Oil Palm (Elaeis guineensis Jacq.) at Seruyan Estate, Minamas \\ Plantation Central Kalimantan.
}

\section{Dwi Djosep Hidayat dan Hariyadi*}

Departemen Agronomi dan Hortikultura, Fakultas Pertanian, Institut Pertanian Bogor (Bogor Agricultural University), Jl. Meranti, Kampus IPB Darmaga, Bogor 16680, Indonesia Telp. \& Faks. 62-251-8629353 e-mail agrohort@apps.ipb.ac.id

*Penulis Korespondensi : hariyadibogor@gmail.com

Disetujui : 21 Mei 2018 / Published Online September 2019

\begin{abstract}
This research was conducted at the Seruyan Estate located in Pembuang Hulu II Village, Hanau Subdistrict, Seruyan Regency, Central Kalimantan from February to June 2015. This research aimed to find out the harvesting facilities, criteria for mature harvest, number of harvest density, quality of harvest, quality of harvest, harvesting and personal protective equipment. In general, Seruyan Estate gardens have carried out garden activities according to standards. The problems found in the harvesting field are the mature quality of the harvest and the quality of the ripples that do not meet company standards.
\end{abstract}

Keywords : palm oil harvesting, harvest density, harvest maturity criteria

\begin{abstract}
ABSTRAK
Penelitian ini dilakukan di Kebun Seruyan Estate yang terletak pada Desa Pembuang Hulu II, Kecamatan Hanau, Kabupaten Seruyan, Kalimantan Tengah dari bulan Februari sampai Juni 2015. Tujuan penelitian ini yaitu mengetahui sarana panen, kriteria matang panen, angka kerapatan panen, kualitas hasil panen, kualitas hanca panen, transport panen dan alat pelindung diri. Secara umun Kebun Seruyan Estate sudah melakukan kegiatan kebun sesuai dengan standar. Permasalah yang ditemukan di bidang pemanenan yaitu kualitas matang panen dan mutu hancak yang belum memenuhi standar perusahaan.
\end{abstract}

Kata kunci : pemanenan kelapa sawit, angka kerpatan panen, kualitas hasil panen 


\section{PENDAHULUAN}

Sampai saat ini luas perkebunan kelapa sawit di Indonesia sudah mencapai >9 juta ha. Hal ini menjadikan Indonesia sebagai produsen kelapa sawit terbesar di dunia. Komoditas Kelapa Sawit merupakan komoditas perdagangan yang menjanjikan. Kelapa sawit (Elaeis guineensis Jacq.) merupakan tanaman perkebunan yang mampu menghasilkan minyak nabati yang lebih besar dari tanaman lain (Setyamidjaja 2006). Minyak kelapa sawit mampu menghasilkan berbagai hasil industri hilir yang dibutuhkan manusia, seperti minyak goreng, mentega, sabun, kosmetik, dan lain sebagainya. Selain itu kelapa sawit juga menjadi slah satu penyumbang devisa terbesar negara dibandingkan komoditas perkebunan lainnya.

Dalam proses budidaya pertanian, kegiatan pemanenan merupakan kegiatan puncak yang ditunggu-tunggu oleh para pemilik perkebunan karena dari panen itulah petani atau perusahaan memperoleh keuntungan. Pahan (2006) menyatakan panen merupakan pekerjaan utama di perkebunan kelapa sawit karena menjadi sumber pemasukan keuangan dari perusahaan 2 melalui penjualan minyak kelapa sawit dan minyak inti sawit, sehingga pengelolaan pemanenan menjadi faktor penentu keberhasilan budidaya tanaman.

Pada perkebunan kelapa sawit milik rakyat, panen merupakan tahap akhir pengelolaan perkebunan, karena TBS (tandan buah segar) langsung dijual ke pabrik atau kebun inti disekitarnya (Hadi, 2004). Usaha perkebunan kelapa sawit rakyat umumnya dikelola dengan model kemitraan dengan perusahaan besar swasta dan perkebunan negara (inti-plasma) (Kiswanto et al. 2008). Manajemen pemanenan mencakup berbagai aspek yang harus diperhatikan untuk mendapatkan hasil yang maksimal. Manajemen pemanenan dilakukan mulai dari peramalan saat panen atau produksi hingga pelaksanaan panen dan pengangkutan buah. Tujuan akhir dari pemanenan adalah memperoleh Tandan Buah Segar (TBS) yang berkualitas baik dengan CPO dan PKO tinggi serta memenuhi standar mutu yang ditetapkan oleh badan internasional. Kegiatan panen harus diperhatikan dan pelaksanaanya harus dilakukan dengan baik untuk memperoleh kualitas maupun kuantitas kelapa sawit yang maksimal. Adapun tujuan dari penelitian ini yaitu mengenai pelaksanaan manajemen pemanenan secara teknis, pengolaan dan menganalisa masalah.

\section{BAHAN DAN METODE}

Penelitian dilaksanakan selama 4 bulan pada bulan Februari 2015 sampai Juni 2015 di Seruyan Estate, Kebun Minamas, Desa Pembuang Hulu II, Kecamatan Hanau, Kabupaten Seruyan, Kalimantan Tengah dari bulan Februari sampai Juni 2015. Pengempulan data berupa data primer diperoleh dengan melakukan kerja langsung dan diskusi langsung dengan karyawan mengenai teknis budi daya tanaman kelapa sawit. Data sekunder diperoleh dari data BPS, dokumen, catatan-catatan, dan laporan-laporan dari perusahaan tempat berlangsungnya praktik kerja lapangan, serta melakukan kajian pustaka yang menunjang dan memadai sebagai bahan acuan dalam penyusunan laporan PKL. Kondisi pada tempat penelitian adalah sebagai berikut.

\section{Letak Geografis dan Wilayah Administratif}

Kebun Seruyan Estate memiliki 2 unit kebun dan 1 unit pabrik yaitu Sekunyir Estate (SKE), Seruyan Estate (SRE), dan Sekunyir Factory (SKF). Kebun Seruyan Estate sendiri terletak di Desa Pembuang Hulu II, Kecamatan Hanau, Kabupaten Seruyan, Kalimantan Tengah. Letak geografis Seruyan Estate berada di titik kordinat 2,391-2,471 ${ }^{\circ} \mathrm{LS}$ dan 111,984$112,083^{\circ}$ BT. Kebun Seruyan Estate merupakan hasil pemekaran dari Kebun Sekunyir Estate pada tahun 2002 dengan luas lahan areal HGU sebesar 4179.4 ha yang di bagi menjadi 3 divisi.

\section{Keadaan Iklim dan Tanah}

Kebun Seruyan Estate memiliki sudut kemiringan lahan rata-rata $0-8 \%$, sehingga kebun ini dapat di klasifikasiakn sebagai kebun yang cukup datar meskipun ada beberapa titik tempat yg sedikit bergelombang dengan kemiringan 9$15 \%$. Berdasarkan hasil data curah hujan tahun 2010-2014 curah hujan rata-rata tahunan pada kebun seruyan yaitu $2635 \mathrm{~mm} /$ tahun dengan ratarata hari hujan 170 hari. Bulan kering kebun seruyan memiliki nilai rata rata 0.6 , bulan basah 9.8 dan bulan lembab sebesar 1.6. selain itu rata rata suhu di kebun seruyan estate berkisar antara 23-28 derajat Celcius berdasarkan perhitungan diatas maka menurut schmidth ferguson kebun seruyan estate termasuk ke dalam tipe iklim A (sangat basah).

\section{Luas Areal Konsesi dan Tata Guna Lahan}

Luas areal Hak Guna Usaha terbagi menjadi dua estate yaitu Sekunyir Estate dengan luasan Kebun Sekunyir 3555.2 ha dan Kebun Seruyan 4179.4 ha sehingga total luasan kebun 
Minamas yaitu 7734.6 ha. Kebun Seruyan Estate terbagi menjadi 3 divisi dengan luasan masing masing divisi yaitu divisi 1 seluas 1134.278 ha, divisi 2 seluas 1075,444 ha, dan divisi 3 seluas 1 023,744 ha yang masing- masing divisi dipimpin oleh satu orang Asisten Kebun. Luas areal jalan dan jembatan kebun seruyan yaitu 114.785 ha, sedangkan luas areal bangunan (emplasment) pada ketiga divisi yaitu 14.28 ha. Kebun Seruyan memiliki lahan okupasi seluas 797.7 ha dan mempunyai areal konservasi seluas 3.6 ha.

\section{Keadaan Tanaman dan Produksi}

Penanaman pertama yang dilakukan oleh kebun Indotruba tengah yaitu pada tahun 1992 dan di ikuti pada tahun 1993 dan 1994. Namun pada tahun 2013 Kebun Seruyan Estate sudah memulai proses peremajaan tanaman. Ada beberapa jenis varietas yg digunakan oleh kebun seruyan estate, yaitu varietas Marihat yang diproduksi oleh Pusat Penelitian Kelapa Sawit (PPKS) dan varietas Socfindo yang diproduksi oleh PT. Socfindo. Stand per Hectare (SPH) Seruyan Estate memiliki nilai yg beragam. Pada TM tahun tanam 1992, 1993, dan 1994 SPM yg digunakan yaitu dengan jarak tanam $9 \mathrm{~m} \mathrm{x} 9 \mathrm{~m} \mathrm{x}$ $9 \mathrm{~m}$ dengan jumlah populasi 136 tanaman/ha. Sedangkan pada TBM tahun tanam 2013, 2014, dan 2015 SPH yg digunakan jarak tanam 7,97 m x 7,97 m x 7,97 m dengan jumlah populasi 178180 tanaman/ha. Perbedaan SPH yang digunakan ini dikarenakan adanya kebijakan perusahaan yang baru saat tanaman akan diremajakan sehingga memiliki populasi tanaman perhektare yg lebih tinggi dari tahun tanam sebelum nya.

\section{Struktur Organisasi dan Ketenagakerjaan}

Kebun Seruyan Estate dipimpin oleh Bapak Ondra Utama selaku Estate Manager (EM) yang memiliki tanggung jawab sebagai pengambil kewenangan dan keputusan dalam pengelolaan suatu kebun. EM memiliki peran untuk mengelola seluruh kebun baik administrasi maupun manajerial di lapangan. EM di Seruyan Estate dibantu langsung oleh 1 senior asisten, 2 asisten divisi dan seorang kepala administrasi (Kasie). Seorang senior asisten bertugas untuk mengoordinasikan asisten divisi, mengelola emplasemen, traksi dan keamanan. Seorang asisten divisi memiliki wewenang dan tanggung jawab penuh terhadap pengelolaan divisi yang dipimpinnya serta mengepalai karyawan divisi yang terdiri atas mandor I, mandor panen, mandor perawatan, mandor pupuk, mandor emplasemen, krani divisi, krani panen, krani buah. Kepala administrasi bertugas untuk mengelolah seluruh administrasi dan keuangan di tingkat kebun meliputi perencanaan biaya kegiatan kebun dan mengatur keuangan kebun. Dalam menjalankan tugas, kepala administrasi dibantu oleh seluruh karyawan administrasi di kantor besar, krani divisi dan tim keamanan. Selain itu pengelolaan mess, gudang, kantor dan sekolah merupakan bagian dari kewenangan seorang kepala administrasi.

Kebun Seruyan Estate memiliki dua sistem ketenagakerjaan, yaitu karyawan staf/pimpinan dan karyawan non staf. Karyawan staf atau pimpinan terdiri dari Estate Manager, Kasie, Senior asisten, dan Asisten. Sedangkan karyawan yang termasuk kedalam non staf terdiri dari karyawan SKU (standar karyawan Unit), yaitu karyawan administrasi kebun/divisi, mandor divisi, pemanen, perawat tanaman, guru TK/SD/SMP, petugas kesehatan, karyawan teknik/transpor, keamanan, serta karyawan harian lepas (KHL).

\section{HASIL DAN PEMBAHASAN}

\section{Pemanenan}

Selain dari areal pembibitan, pendapatan utama sebuah perusahaan perkebunan kelapa sawit juga berasal dari hasil produksi tandan buah segar (TBS). Dikarenakan hal itu agar dapat menghasilkan produksi yang baik perlu adanya sebuah managemen dalam pelaksanaannya. Seruyan Estate menggunakan sistem Blok Harvesting System yaitu suatu sistem potong buah yang terkonsentrasi pada satu daerah kerja (seksi panen) yang telah ditentukan. Tujuan penerapan sistem ini adalah untuk mempermudah supervisi, memaksimalkan produksi serta menekan losses hasil seminimal mungkin. Ada 2 jenis tipe pekerjaan dalam proses pemanenan, pertama adalah pemanen (cutter) tugas dari seorang pemanen yaitu mencari buah matang siap panen sesuai dengan kriteria lalu mengeluarkan nya ke tempat pengumpulan hasil (TPH). Sedangkan tugas seorang pembrondol (picker) yaitu mengutip berondolan sisa. Secara teknis kegiatan pemanenan dilapangan memiliki alur sebagai berikut yaitu :

1. Mempersiapkan alat-alat cutter dan picker (eggrek, angkong, gancu, kapak, karung).

2. Pemanen masuk ke dalam blok untuk mencari buah matang.

3. Saat proses penurunan buah, pelepah sawit yang terpotong dirapikan dan disusun mengelilingi piringan dengan membentuk huruf U (U shaped front stacking). Pelepah harus menjauhi pasar rintis. 
4. Tandan buah yang panjang dipotong menggunakan kapak. Pemotongan dilakukan sebelum pengangkutan menggunakan angkong.

5. Seluruh buah yang dipanen dikeluarkan seluruhnya ke TPH dan disusun. Buah diberi kode/cap berdasarkan nomor pemanen menggunakan brondolan pada gagang buah.

6. Pembrondol masuk kedalam blok untuk mengutip setelah proses pemanenan selesai.

7. Berondolan yang telah dikutip dimasukan kedalam karung eks pupuk.

8. karung berondolan disusun di TPH dan diberi nomor sesuai nomor urut karyawan

9. Pemberondol sebelum diukur dengan tongkat khusus perhitungan berondolan yang telah dikalibrasikan.

\section{Sarana dan Prasarana Panen}

Dalam melakukan kegiatan pemanenan sarana dan prasarana panen menjadi bagian yang penting karena menyangkut hal persiapan alat dan keamanan pada saat proses pemanenan. Alat-alat yang digunakan dalam proses pemanenan antara lain, dodos kecil (tanaman 34 tahun), dodos besar (tanaman 5-8 tahun), pisau egrek ( tanaman $>9$ tahun), gagang egrek, clame egrek, gancu, kampak dan angkong. Sedangkan peralatan alat pelindung diri (APD) pemanenan yaitu helm, sarung tangan, kaus kaki, dan sepatu (gambar)

Penggunaan alat pelindung diri (APD) sangat diwajibkan untuk menghindari dan mengurangi dampak kecelakaan kerja. Tingkat kesadaran pekerja pemanen di Seruyan Estate terhadap penggunanan APD sudah baik namun ada sedikit saja pemenen yang belum menggunakan APD. Terlihat dari beberapa pemanen yang tidak memakai APD saat melaksanakan kegiatan. Persentase pemakaian APD dapat dilihat pada Tabel 1.

Tabel 1 Pemakaian APD

\begin{tabular}{lcrc}
\hline Mandor & \multicolumn{3}{c}{ Pemakaian APD } \\
\cline { 2 - 4 } & Helm-Sepatu & Sepatu Boot \\
& Bot (\%) & $(\%)$ & Helm (\%) \\
\hline A & 80 & 10 & 10 \\
B & 90 & 10 & 0 \\
C & 90 & 0 & 10 \\
\hline Total & 87 & 7 & 7 \\
\hline
\end{tabular}

\section{Kriteria Matang Panen}

Salah satu faktor yang mempengaruhi jumlah dan mutu minyak kelapa sawit yaitu tingkat kematangan buah pada saat dipanen dan penanganannya sampai ke pabrik kelapa sawit (PKS). Kriteria matang panen merupakan kematangan tandan secara fisiologis yaitu tandan telah matang sempurna bentuknya dan kandungan minyak pada buah tersebut optimal (Sastrosayono 2006). Sakah satu ciri yang menandakan tingkat kematangan tandan kelapa sawit yang siap dipanen yaitu adanya 5-10 brondolan jatuh di piringan tanaman kelapa sawit. Tingkat kematangan buah kelapa sawit terbagi menjadi 5 yaitu :

1. unripe (mentah) dengan ciri warna buah hitam kemerahan dan terdapat kurang dari 4 brondolan dengan batas toleransi $0 \%$.

2. under ripe (kurang matang) dengan ciri warna buah kemerahan dan terdapat 5-9 berondolan di piringan dengan batas toleransi $8,0 \%$.

3. ripe (matang) dengan ciri warna buah merah mengkilat dan terdapat lebih dari 10 berondolan di piringan dengan batas tolersansi $90 \%$.

4. empety bunch (janjang kosong) dengan ciri warna buah dominan orange dan berondolan terlepas $>95 \%$ dengan batas toleransi $2 \%$.

5. Old bunch (buah restan) buah kelapa sawit yang sudah dipanen namun tidak terangkut ke pabrik lebih dari 48 jam. Kriteria buah yang boleh dipanen yaitu warna buah orange kemerahan dan memiliki lebih dari 5 berondolan di piringan. Pengamatan kriteria matang panen di Divisi I Seruyan Estate dapat dilihat pada Tabel 2.

Tabel 2 Jumlah brondolan jatuh di piringan sebelum TBS dipanen

\begin{tabular}{lcccc}
\hline Mandor & $\begin{array}{c}\text { Tandan } \\
\text { Contoh }\end{array}$ & $\begin{array}{c}\text { Buah } \\
\text { Matang } \\
\geq 5\end{array}$ & $\begin{array}{c}\text { Tandan } \\
\text { Kosong } \\
95 \% \\
\text { Brondol }\end{array}$ \\
\hline $\mathrm{A}$ & 100 & 1 & 99 & 0 \\
$\mathrm{~B}$ & 100 & 1 & 99 & 0 \\
$\mathrm{C}$ & 100 & 2 & 98 & 0 \\
\hline Total & 300 & 4 & 296 & 0 \\
$\%$ & 100 & 1.3 & 98.6 & 0 \\
\hline Sumber: Pengamatan penulis & $(2015)$ &
\end{tabular}

\section{Angka Kerapatan Panen}

Angka kerapatan panen (AKP) atau taksasi produksi adalah suatu perkiraan produksi hasil tanaman yang dibudidayakan. Taksasi panen harian adalah kegiatan yang dilakukan untuk memperkirakan produksi TBS yang akan diperoleh esok hari. Hal tersebut juga 
bisa memperkirakan kebutuhan tenaga pemanen dan memperkirakan jumlah transportasi untuk mengangkut hasil panen. Menurut Fauzi et al.

\begin{tabular}{lcccccc}
\hline Blok Panen & $\begin{array}{c}\text { Jumlah } \\
\text { Populasi }\end{array}$ & $\begin{array}{c}\text { Blok } \\
\text { Contoh }\end{array}$ & $\begin{array}{c}\text { Jumlah } \\
\text { Pokok Contoh }\end{array}$ & $\begin{array}{c}\text { Jumlah } \\
\text { Tandan Matang }\end{array}$ & $\begin{array}{c}\text { AKP } \\
\text { Taksasi (\%) }\end{array}$ & $\begin{array}{c}\text { AKP } \\
\text { Realisasi (\%) }\end{array}$ \\
\hline B25-B28 & 20502 & B26 & 5214 & 55 & 21.07 & 19.50 \\
A33-A34 & 11417 & A33 & 5708 & 72 & 25.26 & 23.50 \\
A25-A28 & 24006 & A25 & 5653 & 68 & 24.02 & 24.73 \\
A24-A22 & 16893 & A22 & 5724 & 57 & 19.93 & 22.02 \\
B26-B28 & 15288 & B26 & 5228 & 48 & 18.39 & 20.30 \\
B29-B32 & 20840 & B31 & 5589 & 58 & 20.78 & 18.63 \\
\hline Rata-rata & & & & 21.57 & 21.45
\end{tabular}

(2008) kerapatan panen merupakan sejumlah buah yang diperkirakan bisa dipanen dicirikan dengan brondolan yang terdapat di piringan sebanyak lima brondolan. Hasil AKP taksasi dan realisasi dapat dilihat di Tabel 3.

Tabel 4 hasil uji T-student pada taraf 5\%

\begin{tabular}{cccccc}
\hline Source & DF & Type ISS & $\begin{array}{c}\text { Mean } \\
\text { Square }\end{array}$ & F Value & P-value \\
\hline & & & & & \\
akp & 1 & 0.049 & 0.049 & 0.01 & 0.9304 \\
\hline
\end{tabular}

\section{Kualitas Hasil Panen}

Salah satu parameter penilaian kualitas tandan buah segar yaitu dari tingkat kematangan buah. Oleh sebab itu pemeriksaan mutu buah menjadi hal yang harus dilakukan. Para pemanen harus bisa melihat buah yang benar-benar siap dipanen melalui kriteria brondolan yang ada di piringan. Hasil pengamatan kualitas buah dapat dilihat di Tabel 5.

\section{Mutu Hanca Panen}

Mutu hanca panen bertujuan untuk memeriksa dan mengetahui hasil kerja pemanen terhadap kehilangan hasil panen di hanca. Dengan adanya sistem BHS setiap pemanen memiliki hanca tetap sehingga para pemanen memiliki tanggung jawab terhadap hanca.
Tabel 3 Hasil AKP taksasi dan realisasi di Divisi I SRE

kebih mudah untuk menilai hasil pekerjaan dari para pemanen. Kualitas hanca yang baik akan pula berpengaruh terhadap produksi perusahaan karena dapat meminimalisir kehilangan hasil (losses). Hasil pengamatan mutu hanca penen dapat dilihat pada tabel 6.

Tabel 6 Pengamatan Hanca Panen

\begin{tabular}{|c|c|c|c|c|}
\hline Pemanen & $\begin{array}{c}\text { Tanaman } \\
\text { Sampel }\end{array}$ & $\begin{array}{c}\text { Brondolan } \\
\text { Tinggal }\end{array}$ & $\begin{array}{c}\text { Jumlah } \\
\text { TBS } \\
\text { Tinggal }\end{array}$ & $\begin{array}{c}\text { TBS Tidak } \\
\text { Dipanen }\end{array}$ \\
\hline 1 & 100 & 11 & - & - \\
\hline 2 & 100 & 24 & - & - \\
\hline 3 & 100 & 9 & - & 2 \\
\hline 4 & 100 & 14 & - & - \\
\hline 5 & 100 & 18 & - & - \\
\hline 6 & 100 & 15 & - & - \\
\hline 7 & 100 & 21 & - & - \\
\hline 8 & 100 & 19 & - & 1 \\
\hline 9 & 100 & 14 & - & - \\
\hline 10 & 100 & 25 & - & - \\
\hline Total & 1000 & 170 & & 3 \\
\hline LF/Palm & \multicolumn{4}{|c|}{0.17} \\
\hline
\end{tabular}

Tabel 5 Hasil pengamatan kualitas buah

\begin{tabular}{rccccccc}
\hline TPH & $\begin{array}{c}\text { Jumlah } \\
\text { Sampel TBS }\end{array}$ & $\begin{array}{c}\text { Unripe } \\
(\%)\end{array}$ & $\begin{array}{c}\text { Under } \\
\text { Ripe }(\%)\end{array}$ & $\begin{array}{c}\text { Ripe } \\
(\%)\end{array}$ & $\begin{array}{c}\text { Over ripe } \\
(\%)\end{array}$ & $\begin{array}{c}\text { Empty } \\
\text { Bunch }(\%)\end{array}$ & $\begin{array}{c}\text { Long } \\
\text { Stalk }(\%)\end{array}$ \\
\hline 1 & 23 & 0.00 & 13.04 & 82.60 & 8.69 & 0.00 & 0.00 \\
2 & 24 & 0.00 & 12.50 & 79.16 & 4.16 & 0.00 & 0.00 \\
3 & 29 & 0.00 & 10.34 & 86.20 & 3.44 & 0.00 & 0.00 \\
4 & 28 & 0.00 & 3.57 & 96.42 & 0.00 & 0.00 & 0.00 \\
5 & 10 & 0.00 & 0.00 & 100.00 & 0.00 & 0.00 & 0.00 \\
6 & 29 & 0.00 & 6.89 & 86.20 & 6.89 & 3.44 & 0.00 \\
7 & 9 & 0.00 & 0.00 & 100.00 & 0.00 & 0.00 & 0.00 \\
8 & 22 & 0.00 & 4.54 & 95.23 & 0.00 & 0.00 & 0.00 \\
9 & 19 & 0.00 & 5.26 & 84.22 & 10.52 & 0.00 & 0.00 \\
10 & 16 & 0.00 & 6.25 & 93.75 & 0.00 & 0.00 & 0.00 \\
\hline Rata-rata & 21 & 0 & 5.55 & 90.378 & 3.37 & 0.3 & 0 \\
\hline
\end{tabular}


standart

0

$<8$

90

2

0

$<5$

Sumber: Pengamatan Penulis (2015)

\section{Sistem Supervisi dan Denda}

Kualitas buah yang baik sangat diutamakan untuk mendapatkan hasil yang baik dalam proses produksi kelapa sawit. Oleh sebab itu kegiatan supervisi atau pengawasan sangat penting untuk memastikan kualitas buah yang dikirim ke pabrik kelapa sawit sudah memenuhi standar. Selain itu para supervisi juga bertugas untuk mengukur besaran kecilnya losses. Salah satu cara untuk menekankan tujuan tersebut yaitu dengan cara pemberian denda kepada pemanen yang melakukan kesalah dalam proses pemanenan. Pengawasan panen dilakukan oleh departement Quality Assurance (QA), Asisten Divisi, Mandor I, Mandor Panen dan Kerani Panen. Parameter pemeriksaan/pengawasan panen meliputi mutu buah dan mutu hancak. Berikut adalah kriteria mutu buah.

Tabel 7 Kriteria mutu buah.

\begin{tabular}{lc}
\hline Kriteria mutu buah & Batas toleransi \\
\hline Unripe & $0 \%$ \\
Under ripe & $8,0 \%$ \\
Ripe & $90 \%$ \\
Empty bunch & $2 \%$ \\
Old crop & 48 jam \\
Long stalk & $5 \%$ \\
Kontaminasi & $0 \%$ \\
\hline Sumber : Vademi
\end{tabular}

Sumber : Vademicum Minamas Plantation 2004

Pengawasan kegiatan pemanenan harus dilakukan setiap hari panen demi menjaga kualitas panen yang baik. Peran mandor panen sangat dibutuhkan untuk mengawasi hancak pemanen. Untuk memeriksa mutu buah ditugaskan seorang kerani panen. Tugas kerani panen antaralian :

1. Memeriksa dan menghitung buah serta berondolan di TPH serta memberi cap pada gagang buah sebelum diangkut ke PKS.

2. Mencatat hasil pemeriksaan buah kedalam buku penerimaan buah kelapa sawit.

3. Mengisi laporan premi potong buah.

4. Menyampaikan hasil premi kemarin.

5. Melakukan koordinasi dengan mandor panen bila menemukan buah yang tidak sesuai dengan kriteria di TPH saat melakukan pemeriksaan dan memberikan teguran atau denda terhadap pemanen.

Pemberian sanksi denda kepada pemanen bertujuan untuk memberi manfaat konstruktif dalam menegakkan disiplin panen dan budaya tertib kerja kepada pemanen. Besaran denda yang akan dikenakan kepada pemanen bergantung pada jenis dan banyaknya kesalahan yang dilakukan oleh pemanen. Besaran nilai denda di lapangan dan di TPH oleh kebun Seruyan Estate dapat dilihat pada Tabel 8 dan Tabel 9.

Tabel 8 Besaran nilai denda di lapangan

Penilaian di Lapangan

Besaran Denda (Rp)

Berondolan tertinggal di piringan 500 pokok $^{-1}$

Buah matang tidak dipanen $\quad 100 \mathrm{~kg}^{-1}$

TBS hasil panen tertinggal $\quad 100 \mathrm{~kg}^{-1}$

Susunan pelepah tidak di

gawangan mati

Pelepah sengkleh terkena alat

panen

300 pokok $^{-1}$

Sumber : Kantor Seruyan Estate (2004)

Tabel 9 Besaran nilai denda di TPH

Penilaian di TPH Besaran Denda (Rp)

Buah mentah $\quad 500 \mathrm{~kg}^{-1}$

Gagang panjang 200 tandan-1

Tandan kosong ikut

disusun di TPH 500 tandan-1

Sumber : Kantor Seruyan Estate (2004)

\section{Premi Panen}

Setiap pemanen memiliki jumlah target panen harian (basis). Basis panen adalah jumlah minimun TBS kelapa sawit yang harus dipanen dalam satu hari sesi panen. Beberapa hal yang menentukan basis panen yaitu tinggi tanaman, topografi, berat janjang rata-rata dan dikelompokkan berdasarkan tahun tanam. Pemanen yang mendapatkan hasil panen melebihi basis maka akan diberikan upah tambahan (premi). Pemberian premi panen bertujuan untuk memberi penghargaan kepada pekerja yang memiliki hasil kerja diatas standar yang telah ditentukan (basis borong). Selain itu pemberian premi juga diharapkan dapat menaikkan output (janjang hk-1) dan memupuk rasa tanggung jawab pekerja.

Premi panen dibagi menjadi 3 jenis yaitu : premi siap borong, yaitu premi yang diberikan kepada pemanen apabila jumlah janjang panen sama dengan atau lebih dari jumlah janjang basis borong yang telah ditentukan. Premi lebih borong yaitu premi yang diberikan apabila pemanen memperoleh jumlah janjang panen lebih dari jumlah janjang basis borong yang telah ditentukan. Premi pengutip berondolan yaitu premi yang diberikan kepada pemberondol apabila jumlah berondolan $(\mathrm{Kg})$ lebih besar dari pada basis berondolan $(\mathrm{Kg})$. Besaran basis borong seorang pemberondol yaitu $200 \mathrm{Kg}$ dengan lebih borong $\mathrm{Rp} 170 \mathrm{Kg}^{-1}$. 
Ketentuan basis borong dan premi panen kebun Seruyan Estate dapat dilihat pada Tabel 10.

Tabel 10 Ketentuan basis borong dan premi panen kebun Seruyan Estate

\begin{tabular}{ccccccc}
\hline $\begin{array}{c}\text { Tahun } \\
\text { Tanam }\end{array}$ & \multicolumn{3}{c}{ Basis Borong } & \multicolumn{3}{c}{ Premi Siap Borong } \\
\hline & P0 & P1 & P2 & P0 & P1 & P2 \\
& $(\mathrm{jjg})$ & $(\mathrm{jjg})$ & $(\mathrm{jjg})$ & $(\mathrm{Rp})$ & $(\mathrm{Rp})$ & $(\mathrm{Rp})$ \\
\cline { 2 - 7 } 1992 & 56 & 78 & 101 & 3500 & 9000 & 17000 \\
1993 & 71 & 99 & 128 & 3500 & 9000 & 17000 \\
1994 & 78 & 109 & 140 & 3500 & 9000 & 17000 \\
\hline
\end{tabular}

Selain para pemanen, para mandor panen, kerani panen dan mandor 1 juga akan mendapatkan premi panen. Berikut adalah perhitungan premi :

Mandor panen

$=\frac{\text { jumlah premi pemanen }+ \text { pemberondol }}{\text { jumlah pemanen dan pemberondol }} \times 150 \%$

Krani panen

$=\frac{\text { jumlah premi pemanen }+ \text { pemberondol }}{\text { jumlah pemanen dan pemberondol }} \times 125 \%$

Mandor 1

$=\frac{\text { jumlah premi pemandor panen }}{\text { jumlah mandor panen }} \times 150 \%$

\section{Pengangkutan Buah}

Sistem pengangkutan buah menjadi salah satu faktor penting untuk menentukan kualitas minyak kelapa sawit (MKS). Semakin lama tandan buah segar (TBS) hasil panen dievakuasi menuju PKS maka kerusakan kelapa sawit akibat asam lemak bebas (ALB) akan semakin meningkat. Oleh sebab sistem transportasi menjadi salah satu faktor penting dalam mengumpulkan dan mengangkut hasil panen menuju ke pabrik dengan meminimalkan kerusakan pada buah. Pengangkutan buah harus mengangkut seluruh buah dan berondolan dengan secepat mungkin sehingga tidak menyisakan buah restan. Ada dua jenis kendaraan yang digunakan kebun Seruyan Estate yaitu dump truk ps kapasitas 7.5 ton dan Hino kapasitas 12 ton. Pada kegiatan pengangkutan buah ada 4 karyawan yang berkerja. 1 orang sebagai driver dan 3 orang sebagai pemuat buah. Pelaksanaa kegiatan evakuasi buah dimulai dari buah yang pertama kali dipanen .

Kegiatan diawali dengan perhitungan jumlah buah dan berondolan oleh kerani transport. Selanjutnya buah akan dinaikan ke truk oleh para pemuat.Truk yang sudah penuh akan dipasangi jaring yang berfungsi sebagai safety aagar buah tidak jatuh. Alat pelindung diri yang digunakan oleh para pemuat yaitu sarung tangan, sepatu, dan helm. Sedangkan alat yang digunakan adalah tojok. Untuk menjaga kualitas hasil dan mengurangi kontaminasi pada CPO, para pengangkut harus meminimalisir kotoran seperti pasir, janjang kosong dan gagang TBS. Waktu rata-rata yang dibutuhkan untuk memuat buah yaitu 1.5-2 jam.

Pengemudi akan mengirimkan buah setelah sebelumnya mendapatkan surat pengantar buah (SPB) oleh mandor. Surat ini menjadi syarat agar truk bisa masuk ke dalam pabrik kelapa sawit. Waktu rata-rata yang dibutuhkan untuk menuju pabrik yaitu 30 menit. Sesampainya di pabrik truk akan langsung ditimbang bobot keseluruhan nya dengan kondisi mesin mati dan para penumpang beserta supir yang sudah turun dari truk. Setelah ditimbang buah akan langsung di drop ke loading pabrik. Setelah muatan kosong truk akan kembali ditimbang. Selisih antara penimbangan pertama dan kedua itu akan menjadi bobot buah yang telah dikirim. Hasil penimbangan bobot akan tertera pada surat pengiriman buah. Waktu yang dibutuhkan dalam proses damp buah yaitu 10 menit. Bukti penimbangan buah akan diserahkan pada security pabrik, krani transport dan driver.

\section{KESIMPULAN}

Secara umum seluruh kegiatan pengelolaan kebun kelapa sawit di kebun Seruyan Estate sudah sesuai dengan standar perusahaan dengan baik. Manajemen pemanenan yang dilakukan sudah memenuhi standar prosedur perusahaan. Namun pada kegiatan kualitas hasil panen dan mutu hanca panen belum memenuhi standar perusahaan. Beberapa hal yang dapat mempengaruhi kegiatan pemanenan yaitu topografi, alat panen, kondisi hanca serta ketelitian pemanen.

\section{DAFTAR PUSTAKA}

Fauzi Y.,Y.E. Widiastuti, I. Satyawibawa, R. Hartono. 2008. Kelapa Sawit: Budidaya Pemanfaatan Hasil dan Limbah Analisis Usaha dan Pemasaran Edisi Revisi. Penebar Swadaya, Jakarta.

Hadi, M. 2004. Teknik Berkebun Kelapa Sawit. Adicita Karya Nusa, Yogyakarta.

Kiswanto, J.H. Purwanta, B. Wijayanto. 2008. Teknologi Budi Daya Kelapa Sawit. Agro Inovasi, Bandar Lampung. 
Pahan, I. 2006. Panduan Lengkap Kelapa Sawit. Penebar Swadaya, Jakarta.

Sastrosayono, S. 2003 Budidaya Kelapa Sawit. Agromedia Pustaka, Jakarta.
Setyamidjaja, D. 2006. Kelapa Sawit. Kanisius, Yogyakarta. 